Review Article

\title{
Inhibition of Adenylyl Cyclase Type 5 Increases Longevity and Healthful Aging through Oxidative Stress Protection
}

\author{
Stephen F. Vatner, Ronald E. Pachon, and Dorothy E. Vatner \\ Departments of Cell Biology \& Molecular Medicine and Medicine, New Jersey Medical School, Rutgers University, \\ Newark, NJ 07103, USA \\ Correspondence should be addressed to Stephen F. Vatner; vatnersf@njms.rutgers.edu
}

Received 2 January 2015; Revised 10 March 2015; Accepted 13 March 2015

Academic Editor: Vincent Pialoux

Copyright (c) 2015 Stephen F. Vatner et al. This is an open access article distributed under the Creative Commons Attribution License, which permits unrestricted use, distribution, and reproduction in any medium, provided the original work is properly cited.

\begin{abstract}
Mice with disruption of adenylyl cyclase type 5 (AC5 knockout, KO) live a third longer than littermates. The mechanism, in part, involves the MEK/ERK pathway, which in turn is related to protection against oxidative stress. The AC5 KO model also protects against diabetes, obesity, and the cardiomyopathy induced by aging, diabetes, and cardiac stress and also demonstrates improved exercise capacity. All of these salutary features are also mediated, in part, by oxidative stress protection. For example, chronic beta adrenergic receptor stimulation induced cardiomyopathy was rescued by AC5 KO. Conversely, in AC5 transgenic (Tg) mice, where AC5 is overexpressed in the heart, the cardiomyopathy was exacerbated and was rescued by enhancing oxidative stress resistance. Thus, the AC5 KO model, which resists oxidative stress, is uniquely designed for clinical translation, since it not only increases longevity and exercise, but also protects against diabetes, obesity, and cardiomyopathy. Importantly, inhibition of AC5's action to prolong longevity and enhance healthful aging, as well as its mechanism through resistance to oxidative stress, is unique among all of the nine $\mathrm{AC}$ isoforms.
\end{abstract}

\section{Introduction}

Adenylyl cyclase (AC) is a ubiquitous enzyme which regulates all organs and catalyzes the conversion of ATP to cAMP. There are nine major mammalian AC isoforms; types 5 and 6 are the major isoforms in the heart. Since our laboratory has been primarily involved in cardiovascular regulation, our interest was in disrupting one of the two major isoforms in the heart, type $5 \mathrm{AC}$ ( $\mathrm{AC} 5$ knock out (KO)), to see how regulation of cardiac function is altered. We found that the AC5 KO heart was protected against the stresses of chronic pressure overload [1] and chronic catecholamine stimulation [2, 3]. However, even more interesting and potentially important were our other findings of the salutary effects of AC5 inhibition, not necessarily related to the heart. We also studied these mice for 3 years and found that they lived a third longer than wild type (WT) [4]. Although longevity models are important, the translational value for these studies is limited, unless the model also improves healthful aging. In fact older individuals often are not interested in expanding life span, if it is accompanied by many of the limitations observed in the elderly, for example, exercise intolerance, diabetes, and obesity. Importantly the AC5 KO model also promotes healthful aging, as it enhances exercise capacity, and protects against diabetes and obesity and diabetic cardiomyopathy [5] Indeed the AC5 KO model shares many of the same features of the most commonly studied model of longevity and protection against obesity, caloric restriction [6]. However, caloric restriction does not improve exercise performance, but, on the contrary, it actually diminishes exercise capacity [7]. There is also one major limitation to the translation of caloric restriction to longevity and protection against diabetes and obesity in patients, that is, compliance due to difficulty in maintaining low calorie or low fat diets. Accordingly, there is considerable need for a novel therapy that might mimic the phenotype of caloric restriction, without the negative aspects of limiting caloric intake. One such model is inhibition of AC5, which has a similar phenotype to caloric restriction [6], but the mice actually eat more than their wild type controls, while weighing less. 


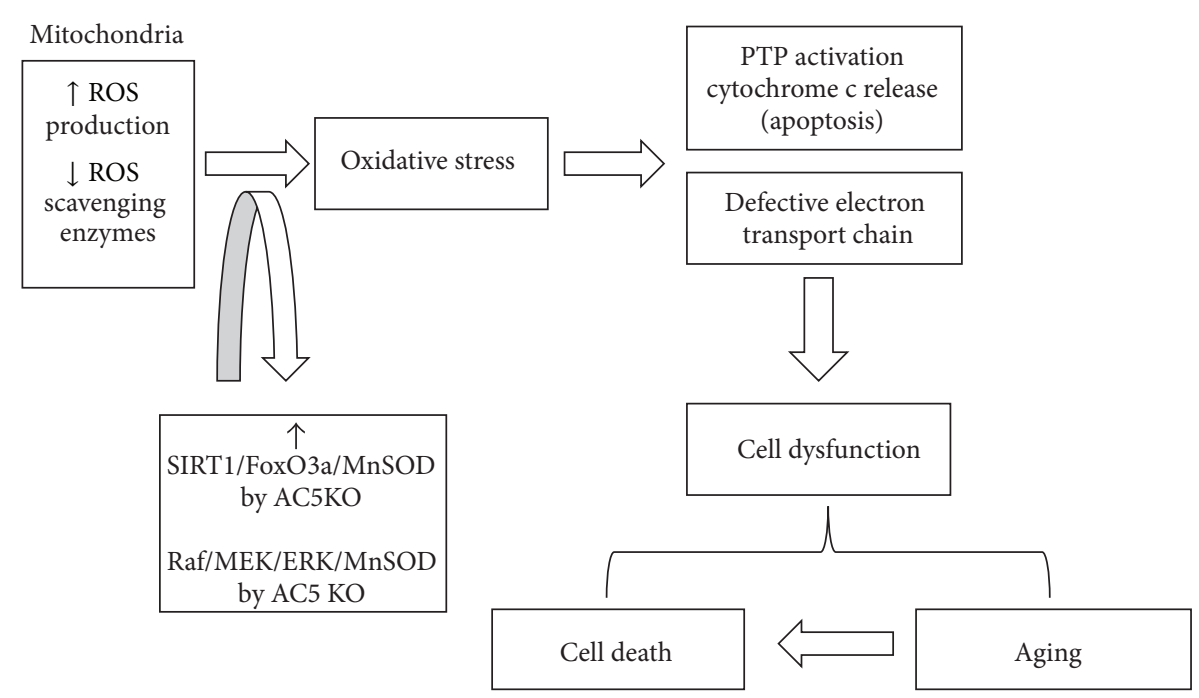

FIGURE 1: Mitochondrial dysfunction and oxidative stress. During the aging process, ROS accumulation and DNA mutation in mitochondria induce oxidative stress, which results in the mitochondrial permeability transition pore (PTP) opening and electron transport chain deficiency, thereby leading to cell dysfunction and cell death. Inhibition of AC5 activates SIRT1/FoxO3a and Raf/MEK/ERK pathways, and both pathways upregulate the antioxidant, $\mathrm{MnSOD}$, resulting in resistance to oxidative stress during aging.

TABLE 1: Longevity and oxidative stress resistance.

\begin{tabular}{|c|c|c|}
\hline $\begin{array}{l}\text { Longevity models related to oxidative } \\
\text { stress resistance }\end{array}$ & $\begin{array}{l}\text { Longevity models not related } \\
\text { to oxidative stress resistance }\end{array}$ & $\begin{array}{l}\text { Longevity models with relationship to oxidative } \\
\text { stress resistance controversial or not studied }\end{array}$ \\
\hline AC5 KO [3-6] & Gpx4 +/- KO [28] & Ames dwarf [29-31] \\
\hline Caloric restriction $[8,32-35]$ & GHR/BP KO $[36,37]$ & FIRKO $[38,39]$ \\
\hline Snell dwarf [40-42] & MIF KO $[43,44]$ & $\mathrm{PAPPA}^{-/-} \mathrm{KO}[45,46]$ \\
\hline GHR KO $[9,40]$ & $\alpha$ MUPA OE $[47,48]$ & $\mathrm{RII} \beta-/-\mathrm{KO}[49]$ \\
\hline Igf- $1 \mathrm{r}^{+/-} \mathrm{KO}[10,50,51]$ & & S6K1-/- KO $[52,53]$ \\
\hline Klotho OE $[11,12,54]$ & & Hct-UCP2 OE [55] \\
\hline p $66^{\text {shc- }--}[13,56]$ & & PEPCK-C OE [57] \\
\hline TRX OE $[14,58]$ & & PtenTg [59] \\
\hline MCAT $[15,60-62]$ & & SIRT6 Tg [63] \\
\hline \multicolumn{3}{|l|}{ MT OE [16] } \\
\hline \multicolumn{3}{|l|}{ Agtr1 $\alpha-/-$ KO [17] } \\
\hline \multicolumn{3}{|l|}{ Irs1-/- KO [18] } \\
\hline \multicolumn{3}{|l|}{ R6/2 Irs2+/- IRS2 Btg KO [19] } \\
\hline \multicolumn{3}{|l|}{ Surf1-/- KO $[21,22,64]$} \\
\hline Mclk1+/- KO $[65,66]$ & & \\
\hline
\end{tabular}

Data are shown as mice models followed by the supporting bibliography in parenthesis [].

One common mechanism that mediates longevity and healthful aging is protection against oxidative stress [4, $6,8-22]$. Table 1 summarizes the most commonly studied longevity models, showing that the majority of these models, as well as the AC5 KO model, have one common theme, that is, protection against oxidative stress. Accordingly, in order to understand the mechanisms mediating the beneficial effects of the AC5 $\mathrm{KO}$ model, it is important to examine its protection against oxidative stress.

\section{Oxidative Stress in Aging and in the AC5 KO (Figures 1 and 2)}

The AC5 KO model of aging protects against oxidative stress by reducing cAMP and protein kinase $A$ (PKA), which in turn activates the Raf/MEK/ERK pathway, which increases MnSOD and protects against oxidative stress [4] (Figures 1 and 2). As noted above, protection against oxidative stress is a common mechanism in longevity models (Table 1). Oxidative 


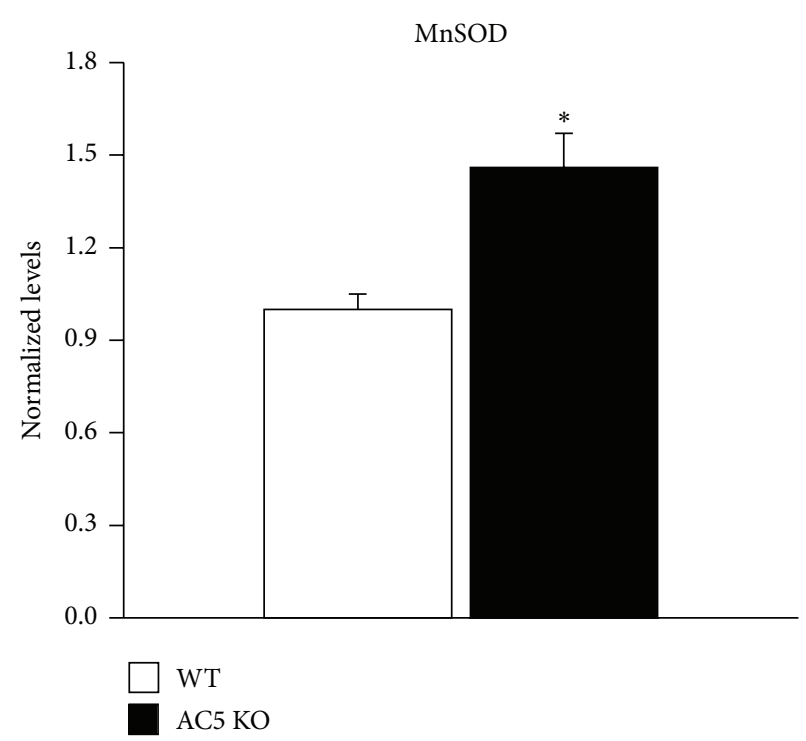

(a)

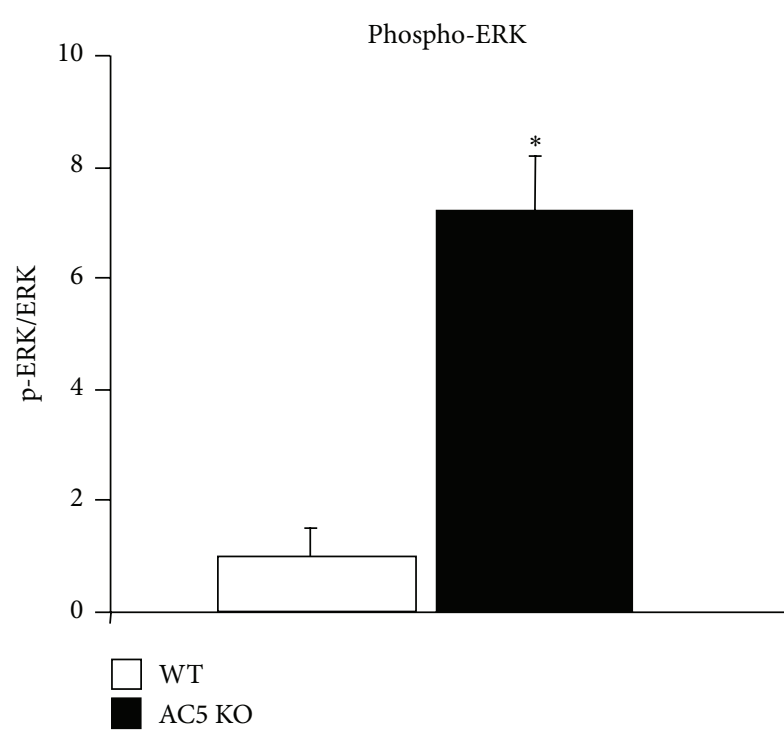

(c)

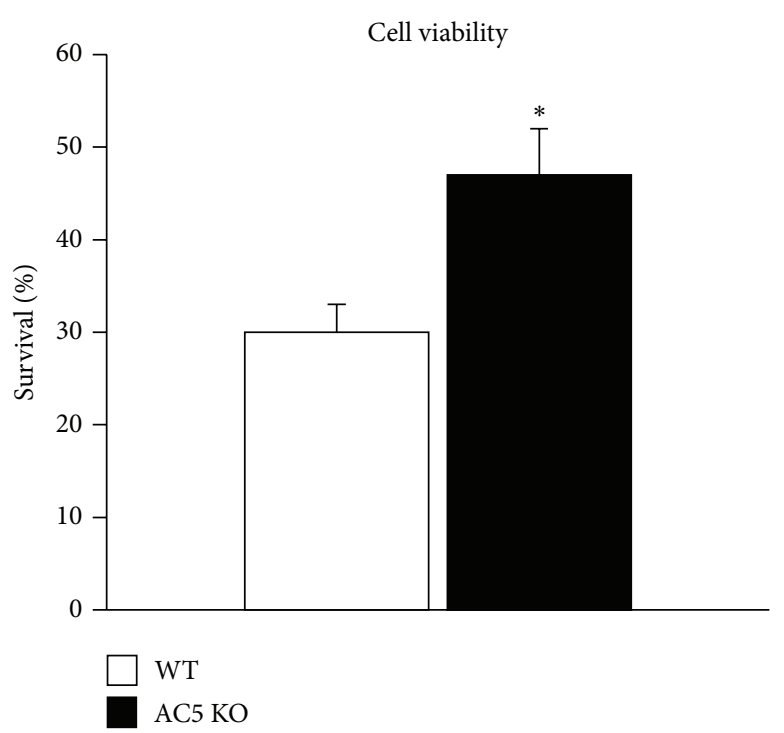

(b)

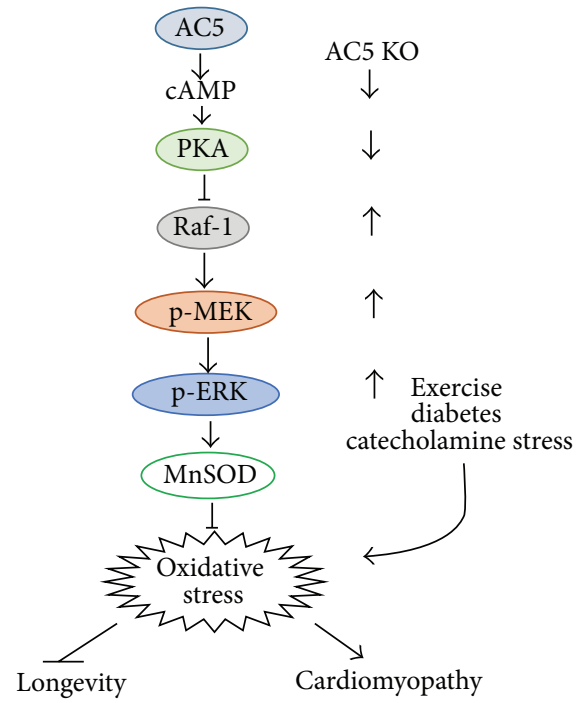

(d)

FIGURE 2: ERK pathway and oxidative stress in aging AC5 KO. (a) Western blotting of MnSOD in the hearts of aging WT and AC5 KO mice. The levels of MnSOD are significantly greater in AC5 KO mice compared to WT mice $\left({ }^{*} P<0.05\right)$. Data are expressed as mean \pm SEM. (b) Cell viability was tested in response to oxidative stress in neonatal cardiac myocytes from AC5 KO and WT. Myocardial cells were treated with $\mathrm{H}_{2} \mathrm{O}_{2}(25 \mu \mathrm{M})$ and evaluated for cell viability using Cell Titer-Blue Cell Viability Assay. AC5 neonatal myocytes showed resistance to oxidative stress and DNA damage $\left({ }^{*} P<0.05\right.$ versus WT). Data are presented as mean \pm SEM. (c) By western blotting, the level of ERK phosphorylation was significantly increased in AC5 KO mice compared with WT $\left({ }^{*} P<0.05\right)$. Data are expressed as mean \pm SEM. (d) Signaling diagram for AC5 regulation of oxidative stress through the ERK pathway is shown. Data is redrawn from Yan et al. [4].

stress is enhanced during the aging process; mitochondria produce less energy (ATP) and also increase the production of reactive oxygen species (ROS) as a product of aerobic metabolism (Figure 1). Furthermore the activity of freeradical scavenging enzymes changes with aging. One mechanism by which oxidative stress is increased in the aging tissue is through increased ROS induced apoptosis and necrosis by opening of the mitochondrial membrane permeability transition pore and release of apoptotic inducing factors, for example, cytochrome c [23] (Figure 1). Oxidative stress has been linked to aging and senescence through the tumorsuppressor $\mathrm{p} 53$ and transcriptional responses, mediated by p44/p53 and p66 [24]. There is also considerable support for the regulation of oxidative stress by the Raf/MEK/ERK pathway [25]. In summary, the mechanism of oxidative stress induced aging seems to be multifactorial, where mitochondrial damage and impaired function play a significant role. The final common pathway for premature cell death has been 
reported to be apoptosis, necrosis, and control of the cell cycle $[26,27]$ (Figure 1), specifically an increase in the percentage of cells stopped at the G0/G1 phase of the cell cycle [26].

To further understand the importance of oxidative stress in aging, the extent to which the major diseases limit longevity must be examined for their relation to oxidative stress. Based on the statistics of the CDC in 2010, the leading causes of death in humans in order of frequency are heart disease, cancer, chronic lower respiratory diseases, stroke, accidents, Alzheimer's disease, diabetes, influenza and pneumonia, nephritis, nephrotic syndrome, and nephrosis. It is important to recognize that most of these diseases are related to oxidative stress. Such is the case for heart disease [67], cancer [68], COPD [69], stroke [70], Alzheimer's [71], diabetes [72], and chronic kidney disease [73]. In mice, the causes of mortality also share oxidative stress mechanisms. The most common cause of death in C57BL/6J mice is neoplasia, including lymphoma and other hematological and nonhematological cancers, followed by chronic kidney and heart diseases [74]. As previously described, these entities have been linked to oxidative stress, further supporting the importance of oxidative stress in limiting longevity.

Perhaps the most convincing evidence for oxidative stress in aging is Progeria, a unique medical condition characterized by premature aging [75], such that teenagers often suffer from atherosclerosis, cardiomyopathy, and coronary artery disease and death. Interestingly, accumulation of oxidized proteins causing DNA damage has been described as the causative effect in this disease [76, 77]. One abnormally formed protein is called lamin A. It is an autosomal dominant mutation involving (LMNA) gene and/or abnormal posttranslational processing (ZMPSTE24) [75, 78].

\section{Oxidative Stress in Exercise}

The AC5 KO model is one of the few aging models known to also improve exercise performance [5]. This is important for two reasons. First, maintained exercise performance is common to longevity, as reduced exercise performance is common to many of the diseases that limit longevity, for example, cardiopulmonary diseases. Secondly, exercise training and conditioning is recognized to be therapeutic to most diseases and is one intervention that can extend longevity [79]. It is therefore important and well established that both resting and contracting skeletal muscles produce ROS. Exercise has been also related to induction of oxidative stress when it is performed at high intensity. However, moderate intensity aerobic exercise enhances endothelium dependent vasodilation through the increased production of nitric oxide [80]. This could be explained by the fact that while high levels of free radicals can damage cellular components, low to moderate level of oxidants play multiple regulatory roles in cells such as the control of gene expression, regulation of cell signaling pathways, and modulation of skeletal muscle force production [80].

There are multiple cellular mechanisms mediating resistance to oxidative stress, by regular moderate exercise. These include reduction of basal formation of oxidants, improvement of the antioxidant defense system, and increased resistance of tissues against ROS damage [81]. Furthermore, in a study using rats, exercise increased total serum antioxidant substances with an additional beneficial effect on lipid profile [82]. More specifically, another study evaluating the relationship of oxidative stress, endothelial dysfunction, and atherosclerosis with physical inactivity in mice showed that decreased physical activity increases vascular NADPH oxidase activity and enhances vascular ROS production, which contributes to endothelial dysfunction and atherosclerosis as opposed to physically active animals [83].

\section{Oxidative Stress in Diabetes and Obesity}

As noted above the AC5 KO mouse shares a common phenotype and genotype with caloric restriction [6], a frequently studied model demonstrating protection against diabetes and aging. The AC5 KO protection against glucose intolerance and insulin resistance and obesity is observed in the animals on a standard diet, but it is even more pronounced when stressed with a high fat diet [84]. The AC5 KO mice weigh less and have less obesity and better serum lipids as well as glucose tolerance and insulin resistance compared to the WT mice [84]. Glucose intolerance and reduced insulin sensitivity have also been linked to oxidative stress mechanisms. Chronic hyperglycemia leads to generation of ROS resulting in increased oxidative stress and destruction of pancreatic cells, critical to insulin secretion [72].

The AC5 KO is also protected from obesity [6], which is also linked to oxidative stress mechanisms. There are several mechanisms by which obesity produces oxidative stress. First, adipose tissue produces certain bioactive substances called adipokines such as IL-6 and leptin, which induce the production of ROS. A second mechanism is that mitochondrial and peroxisomal oxidation of fatty acids can produce ROS in oxidation reactions. And third, there is an overconsumption of oxygen in the mitochondrial respiratory chain [85]. Additionally, the pattern of food consumption in obese patients can potentially exacerbate the cellular damage; lipid rich diets also produce ROS due to modifications in oxygen metabolism contributing to the cell dysfunction induced by obesity [85]. Interestingly, the persistence of obesity in humans has been shown to decrease the activity of antioxidant enzymes in the adipose tissue such as catalase, superoxide dismutase, and glutathionine peroxidase $[85,86]$. This could represent another mechanism involved in the progression of the disease and the development of obesity related complications. Finally, a study in humans confirmed the increased oxidative stress state seen in patients with obesity and diabetes, measuring urinary creatinine-8-epiPGF $2 \alpha$ as a marker of systemic oxidative stress [87]. Taking all the previous evidence together, it is clear that oxidative stress is a common factor in obese and diabetic patients.

\section{Oxidative Stress in Cardiomyopathy and Heart Failure}

There is accumulating evidence that increased oxidative stress is involved in the pathogenesis of various types of cardiomyopathy [88], including dilated $[89,90]$, diabetic $[91,92]$, 
ischemic [93, 94], hypertensive [95], adriamycin-induced [96], and pressure overload-induced cardiomyopathy [9799], as well as beta adrenergic receptor overexpression induced cardiomyopathy $[3,100]$. It is important to note that oxidative stress affects different cell types involved in cardiomyopathy, not just cardiac myocytes. Dysfunction in other cells, such as endothelial cells and fibroblasts, plays an important role in the development of cardiomyopathies, as well.

The AC5 $\mathrm{KO}$ model is also protected against cardiomyopathy and heart failure through oxidative stress mechanisms [3] (Figures 3-5). For example, chronic beta adrenergic receptor ( $\beta$-AR) stimulation induces cardiomyopathy and heart failure by increasing markers of oxidative stress damage including myocyte necrosis and apoptosis [100]. We found that augmenting oxidative stress by mating the $\mathrm{AC} 5 \mathrm{KO}$ mice with MnSOD KO mice resulted in loss of the protection against the decreased cardiac function and increased cardiac fibrosis in response to chronic catecholamine stimulation in the double knockouts (Figure 5) [3,5]. Conversely, when AC5 is overexpressed in the heart, as occurs in the cardiac specific AC5 $\mathrm{Tg}$ mouse, the cardiomyopathy induced by chronic catecholamine stimulation is exacerbated (Figure 5). In this model mating the AC5 Tg mice with MnSOD Tg mice rescues the cardiomyopathy (Figure 5). Furthermore, AC5 $\mathrm{KO}$ can also prevent the cardiomyopathy induced by chronically enhanced $\beta$-AR signaling in mice with overexpressed $\beta 2$-AR also, potentially, through enhancing resistance to oxidative stress [100]. These findings confirm the importance of oxidative stress in the pathogenesis of heart failure in general and in the protection afforded by the AC5 $\mathrm{KO}$ model in particular. The AC5 $\mathrm{KO}$ model is also protected against cardiomyopathies induced by chronic pressure overload [1], diabetes [5], and aging [4].

\section{Mechanisms of AC5 KO Induced Longevity and Oxidative Stress Resistance}

6.1. ERK Signaling Pathway Related to AC5 KO and Oxidative Stress (Figure 2). We previously found that AC5 KO increases longevity and stress resistance via activation of the Raf/MEK/ERK signaling pathway [4]. This finding, based on the reduction in CAMP by AC5, is supported by studies showing that the $\mathrm{AC} / \mathrm{cAMP} / \mathrm{PKA}$ pathway negatively regulates the MEK-ERK signaling pathway [101]. The MEK/ERK signaling pathway is also one of the main stress signaling pathways and central mediators activated in response to oxidative damage $[102,103]$. Previous findings suggested that a decrease in the activation of the Raf/MEK/ERK pathway is associated with aging [104-109]. For example, decreased levels of ERK phosphorylation were observed in senescent fibroblasts $[104,110]$ and hepatocytes from aging rats [111], whereas caloric restriction, a well-recognized mechanism mediating longevity and stress resistance, significantly reduced the age-related decline in ERK activation [111]. The long-lived Snell dwarf mice also exhibits an elevated level of ERK phosphorylation [112]. We have shown an activation of the MEK/ERK signaling pathway in various tissues from long-lived AC-5 KO mice, which is consistent with that found in caloric restricted mice and long-lived Snell dwarf mice. Interestingly, recent studies demonstrated a slower and more prolonged activation of ERK with longevity [113]. Furthermore, the activation of the ERK pathway in response to oxidative stress is reduced with age, while loss of oxidative stress resistance with aging is associated with decreased ERK activity, implying that ERK activation exerts a prosurvival signal against aging induced oxidative stress [111].

In addition, superoxide dismutase (SOD) has been reported as the downstream target of the Cyrl (AC)/cAMP/ PKA pathway in yeast, which induces protection [114]. We have shown that MnSOD, which is a major molecule protecting against oxidative stress, is upregulated in AC5 KO mice (Figure 2(a)) [4] but downregulated, when AC5 is upregulated, as in the AC5 Tg heart (Figure 3(c)) [3]. A deficiency of $\mathrm{SOD}$ is able to induce senescence; for example, homozygous SOD2-/- mice show significant damage to mitochondrial DNA in lung and liver compared to WT mice or heterozygous mice, resulting in a survival rate of only up to seven days after birth due to cardiomyopathy and liver disease [115]. The linkage between SOD and ERK activation is controversial, however. Although EGF-induced phosphorylation of ERK1/2 is attenuated by overexpression of $\mathrm{Cu} / \mathrm{ZnSOD}$ in vascular smooth muscle cells, several other studies have shown that the ERK signaling cascade plays a positive role in overexpression of MnSOD, which protects murine fibrosarcoma cells from apoptosis [116] and suppresses tumor growth in the mac25/IGFBP-rP1-transfected human breast and prostate cancer cell lines [117]. Our findings have proven that MnSOD is the downstream enzyme involved in the ERK signaling cascades [3,4] mediating longevity and stress resistance in AC5 KO mice.

6.2. AC5, SIRT1, FoxO3a, and MnSOD (Figures 3 and 4). As noted above, we found that AC5 KO increases life span and protects against oxidative stress though upregulating the antioxidant, MnSOD [4], whereas MnSOD regulated the cardiomyopathy induced by chronic catecholamine stimulation through the AC5, SIRT1, FoxO3a, and MnSOD pathway [3]. MnSOD is regulated transcriptionally by several transcription factors, such as NF- $\kappa \mathrm{B}, \mathrm{p} 53$, and FoxO3a [118-120]. Among them, FoxO3a is most closely related to the antiaging effects of MnSOD. It is known that FoxO3a is essential for the participation of MnSOD in antiaging mechanisms of various species. In C. elegans, FoxO3a transcriptionally upregulated MnSOD, which induced life span extension [121]. In rats, aging induced downregulation of MnSOD is due to the inactivation of FoxO3a [122]. In human quiescent cells, FoxO3a binds directly to the promoter of MnSOD and protects the cells from oxidative stress [123]. The transcriptional activity of FoxO factor could be activated by deacetylation. SIRT1 is a deacetylase which is able to activate FoxO3a (Figure 4) [118]. Interestingly, we found that the SIRT1/FoxO3/MnSOD pathway is only activated by AC5 and not by AC6 (another major $\mathrm{AC}$ isoform in the heart and brain), indicating a unique regulation of this pathway by AC5 (Figure 3(e)) [3]. The Puigserver lab reported a new short-term SIRT1 activation pathway that involved $\beta$-AR/AC/cAMP/PKA [124]. However, the AC5 $\mathrm{KO}$ model is quite different, since it increases $\mathrm{NAD}^{+}$ 


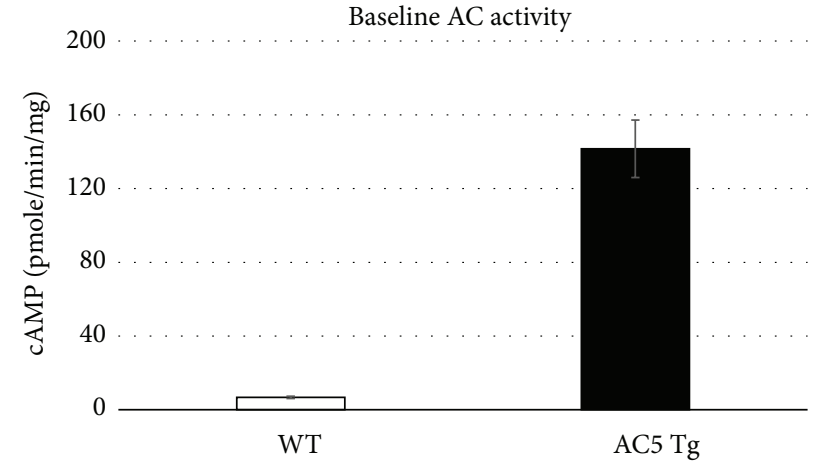

(a)

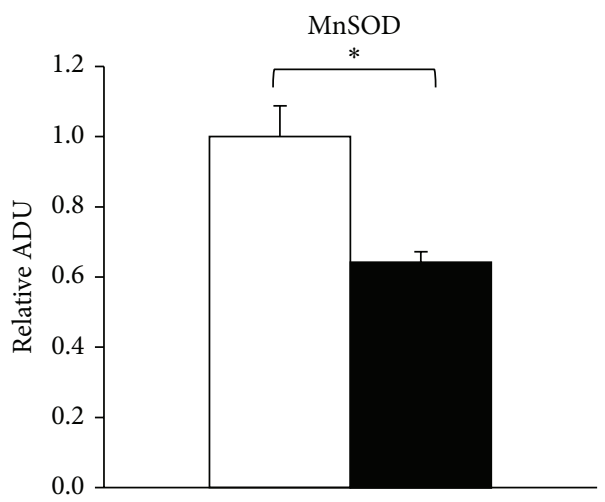

$\square$ WT

- AC5 Tg

(c)

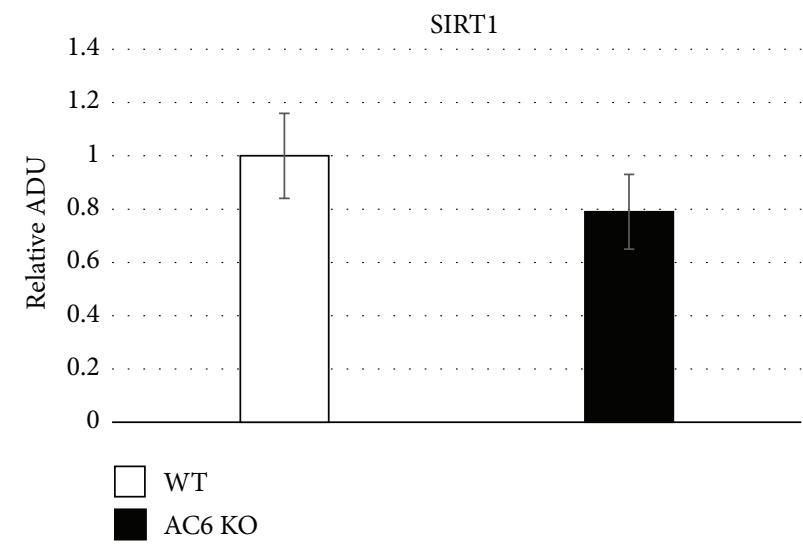

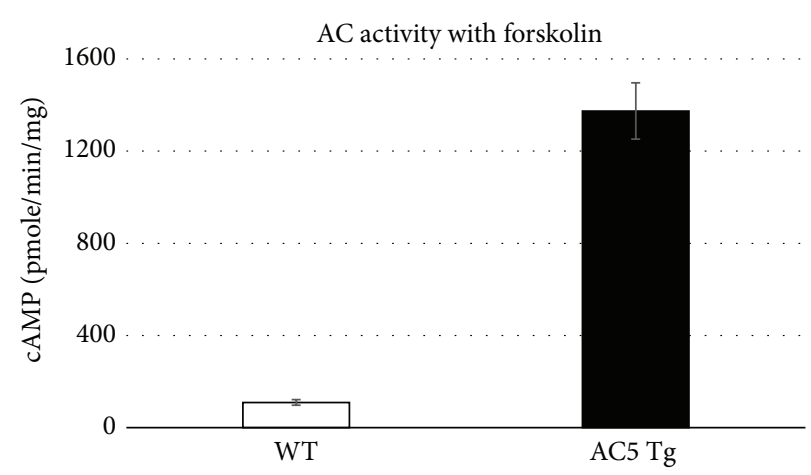

(b)

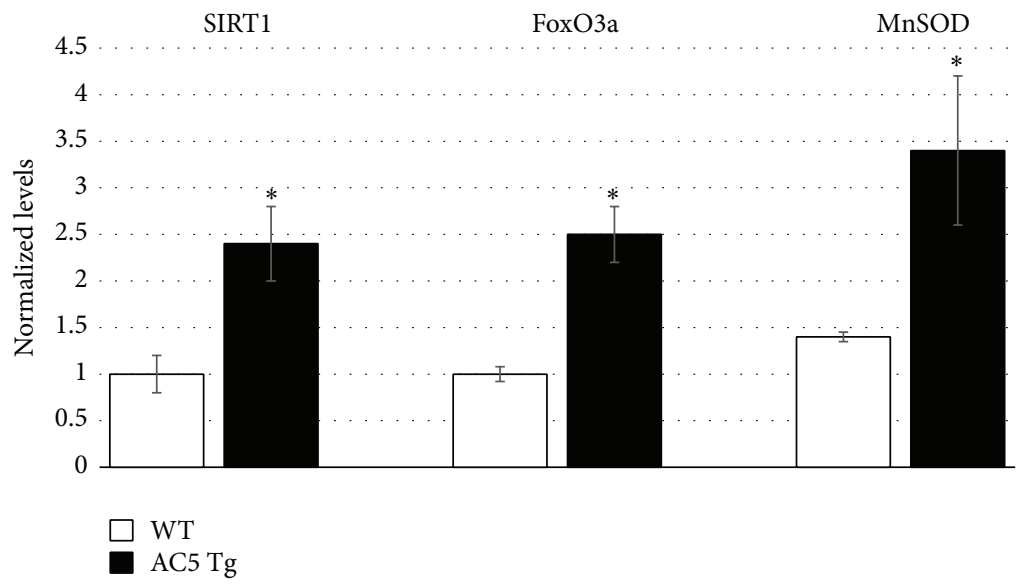

(d)

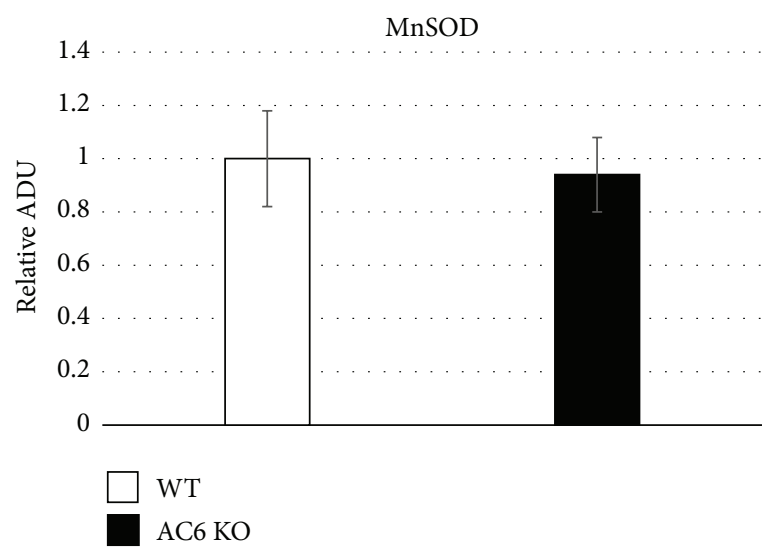

(e)

Figure 3: SIRT1/FoxO3a/MnSOD pathway in AC5 KO, AC5 Tg, and AC6 KO. (a) and (b) AC activity at baseline and in response to forskolin stimulation was enhanced in AC5 Tg mice compared to WT. (c) AC5 regulated MnSOD expression. Downregulation of MnSOD in AC5 Tg mice hearts is shown ( $n$ : 6 per group) $\left({ }^{*} P<0.05\right)$. (d) Expression of SIRT1 by western blotting in the AC5 myocardial cells. SIRT1 was highly expressed compared to WT. $\left({ }^{*} P<0.05\right)$. Expression of FoxO3a by western blotting in AC5 KO mouse hearts is shown. More FoxO3a was expressed in the nucleus of AC5 KO myocytes compared to WT. MnSOD expression increased in AC5 KO hearts $\left({ }^{*} P<0.05\right)$. Data are expressed as mean \pm SEM. (e) SIRT1 and MnSOD expression levels in AC6 KO did not show any difference compared to WT. Data is redrawn from Lai et al. [3]. 


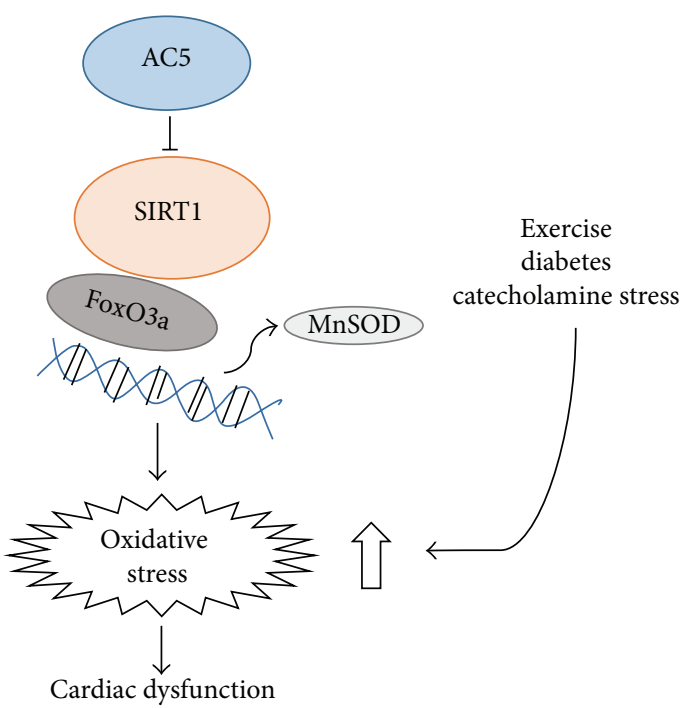

FIGURE 4: Signaling diagram for AC5 regulation of oxidative stress through the SIRT1/FoxO3a pathway.

TABLE 2: Adenylyl cyclase (AC) isoforms, which protect against oxidative stress using the SIRT1/FoxO3/MnSOD pathway.

\begin{tabular}{|c|c|c|c|c|c|c|c|c|c|}
\hline & $\mathrm{AC} 1$ & AC 2 & AC 3 & $\mathrm{AC} 4$ & AC 5 & $\mathrm{AC} 6$ & AC 7 & AC 8 & AC 9 \\
\hline $\begin{array}{l}\text { Oxidative } \\
\text { stress } \\
\text { protection }\end{array}$ & + & $?$ & $?$ & $?$ & + & $?$ & $?$ & $?$ & $?$ \\
\hline SIRT 1 & ? & ? & ? & ? & + & - & ? & ? & ? \\
\hline FoxO3 & $?$ & $?$ & $?$ & $?$ & + & $?$ & $?$ & $?$ & $?$ \\
\hline MnSOD & $?$ & $?$ & $?$ & $?$ & + & - & $?$ & $?$ & $?$ \\
\hline
\end{tabular}

+ Positive, - negative, and ? unknown.

content and SIRT1 protein expression, which chronically maintains $\mathrm{NAD}^{+} /$SIRT1 levels and mitochondrial activity to meet energy requirements. Importantly, the AC5/SIRT1 regulation is unique to $\mathrm{AC} 5$, since our data show that AC5 $\mathrm{KO}$ is resistant to obesity [6], but AC6 KO did not affect body weight and SIRT1 expression [3] (Figure 3), and AC3 KO actually induced obesity [125].

6.3. AC5 Is Unique among the 9 AC Isoforms (Table 2). It is interesting that there are 9 major mammalian isoforms of $\mathrm{AC}$ and many share regulation of the same tissue or organ in the body $[126,127]$; yet they regulate in radically different ways. One example relates to the two major isoforms of $\mathrm{AC}$ in the heart, AC5 and AC6. Inhibiting AC6 shares none of the salutary features of inhibiting AC5, as summarized in this review, with one exception; that is, there are two divergent reports on the regulation of cardiomyopathy by the AC6 KO model: one which claims it is protective [128], as we demonstrated for the AC5 KO $[1,2]$, and another with the opposite conclusions; that is, AC6 KO results in more severe cardiomyopathy [129]. The results for cardiac specific AC 6 transgenic models are also controversial, with some demonstrating protection [130-133] and another showing the reverse [134]. It is even more interesting and pertinent to the topic of oxidative stress that so little is known about $\mathrm{AC}$ isoforms and regulation of oxidative stress. Almost none of the other $8 \mathrm{AC}$ isoforms have been shown to regulate oxidative stress (Table 2), with the tangential exception that $\mathrm{ACl}$ can affect glutamate induced toxicity, which is related to oxidative stress, in cortical neurons. Although little is known about regulation of oxidative stress by the other AC isoforms, the reverse has been shown, that is, oxidative stress regulation of AC isoforms $[135,136]$. In addition, the major mechanisms mediating oxidative stress in the AC5 KO, the SIRT1/FoxO3/ MnSOD pathway, have also not been observed with the other AC isoforms (Table 2). It could well be that other AC isoforms do regulate oxidative stress but that this just has not been studied as of yet and would be an important future direction for AC research.

\section{Summary}

It has been recognized for some time that protection against oxidative stress is a common mechanism mediating longevity (Table 1). This mechanism is also critical in understanding why inhibition of AC5, as in the AC5 KO model, extends longevity. But more importantly, the lesson from the AC5 $\mathrm{KO}$ model is how oxidative stress is important in mediating healthful aging, which when coupled to longevity provides a blueprint for clinical translation. Inhibition of AC5 also protects against diabetes and obesity and cardiomyopathy, while improving exercise performance. Resistance to oxidative stress plays a role in mediating all of these salutary features of the AC5 KO. Importantly, AC5 is the only one of the $9 \mathrm{AC}$ isoforms to demonstrate longevity and healthful aging through resistance to oxidative stress.

\section{Clinical Translation}

Since inhibition of AC5 extends longevity and protects against diabetes, obesity, and cardiomyopathy, while improving exercise tolerance, it naturally becomes an important mechanism for clinical translation. There have been recent clinical studies supporting our findings in the AC5 $\mathrm{KO}$ model. The clinical genome wide association studies have identified single nucleotide polymorphisms (SNPs) in the ADCY5 gene associated with increased type 2 diabetes risk [137], which is the inverse of AC5 inhibition and therefore consistent with our findings. However, it is difficult to isolate the specific action of one gene in human genome studies, as we have done by disrupting the AC5 gene in mice. Unfortunately disrupting the AC5 gene in patients is not feasible and therefore it becomes necessary to identify a pharmacological inhibitor of AC5. One example of a pharmacological compound that replicates many of the features of AC5 inhibition is an FDA approved antiviral drug, Vidarabine [138], which protects against the development of cardiomyopathy in mice [139]. However, this drug is not purely an AC5 inhibitor and has the disadvantage that it cannot be administered orally. Accordingly, further work is required to develop a nontoxic AC5 inhibitor that is soluble and can be given to patients orally. 
Inhibiting oxidative stress rescues enhanced ISO cardiomyopathy in AC5 Tg

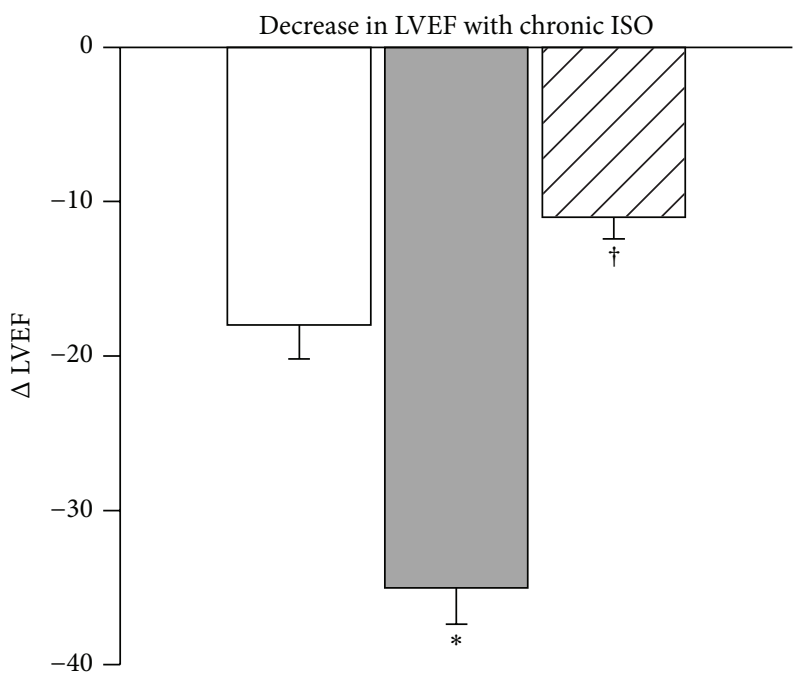

(a)

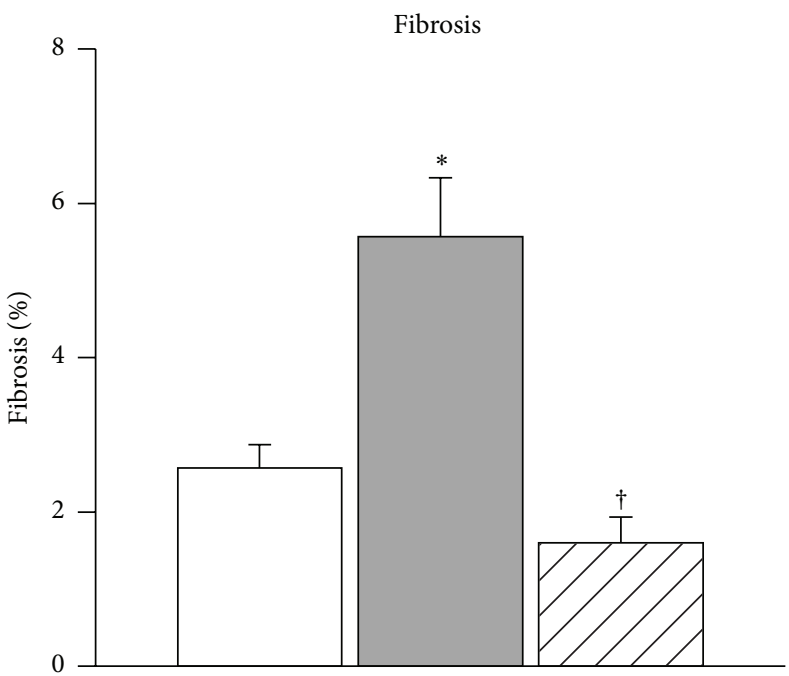

(b)

Increasing oxidative stress blocks the rescue of ISO cardiomyopathy in AC5 KO

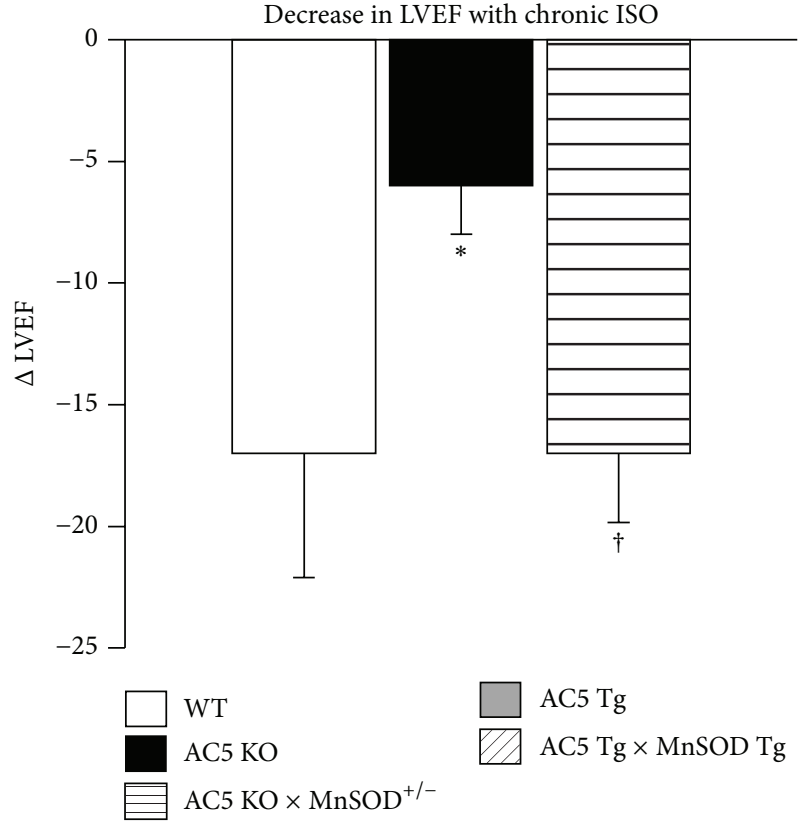

(c)

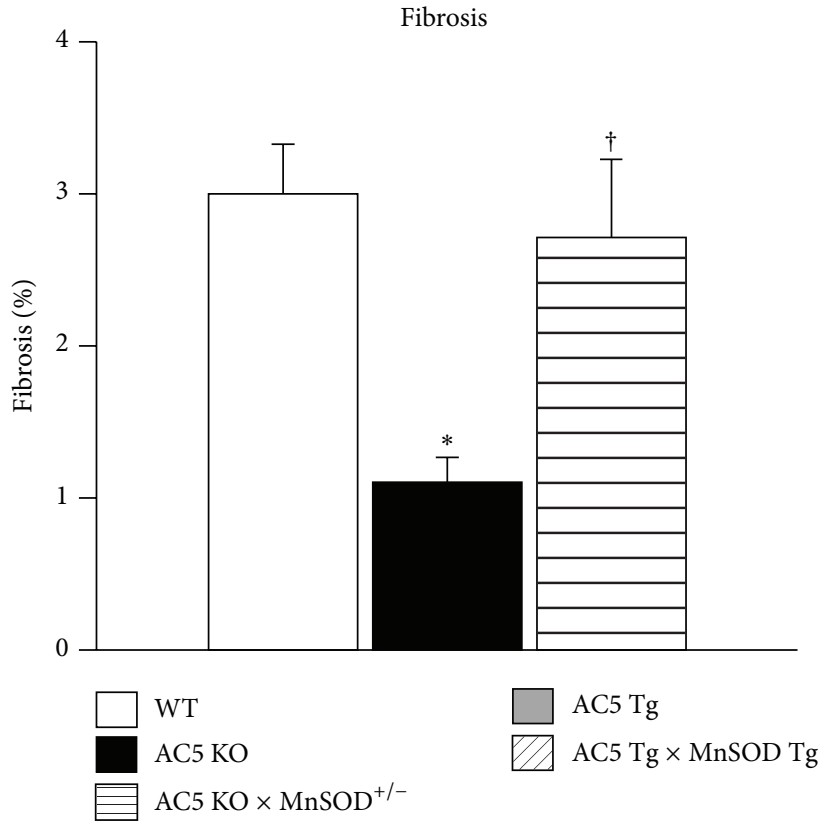

(d)

Figure 5: The effects of chronic isoproterenol (ISO) on AC5 Tg hearts ((a) and (b)). Chronic ISO exacerbated cardiomyopathy in AC5 Tg compared with WT, as reflected by a greater decrease in left ventricular ejection fraction (LVEF) (a) and more fibrosis $(b)\left({ }^{*} P<0.05\right)$. Mating the AC5 Tg mice with MnSOD Tg (AC5 Tg $\times$ MnSOD Tg) mice rescued ISO cardiomyopathy. The effects of chronic ISO on AC5 KO hearts are shown ((c) and (d)). Chronic ISO reduced cardiomyopathy in AC5 KO compared with WT, as reflected by less of a decrease in LVEF (a) and less fibrosis (b). Mating the AC5 KO mice with MnSOD heterozygous mice (AC5 $\mathrm{KO} \times \mathrm{MnSOD}^{+/-}$) eliminated the protective effects of AC5 KO with chronic ISO. ISO: isoproterenol. ${ }^{*} P<0.05$. Data is redrawn from Lai et al. [3].

\section{Conflict of Interests}

The authors declare that there is no conflict of interests regarding the publication of this paper.

\section{Authors' Contribution}

Stephen F. Vatner and Ronald E. Pachon contributed equally to this study. 


\section{References}

[1] S. Okumura, G. Takagi, J.-I. Kawabe et al., "Disruption of type 5 adenylyl cyclase gene preserves cardiac function against pressure overload," Proceedings of the National Academy of Sciences of the United States of America, vol. 100, no. 17, pp. 9986-9990, 2003.

[2] S. Okumura, D. E. Vatner, R. Kurotani et al., "Disruption of type 5 adenylyl cyclase enhances desensitization of cyclic adenosine monophosphate signal and increases Akt signal with chronic catecholamine stress," Circulation, vol. 116, no. 16, pp. 1776-1783, 2007.

[3] L. Lai, L. Yan, S. Gao et al., "Type 5 adenylyl cyclase increases oxidative stress by transcriptional regulation of manganese superoxide dismutase via the SIRT1/FoxO3a pathway," Circulation, vol. 127, no. 16, pp. 1692-1701, 2013.

[4] L. Yan, D. E. Vatner, J. P. O'Connor et al., “Type 5 adenylyl cyclase disruption increases longevity and protects against stress," Cell, vol. 130, no. 2, pp. 247-258, 2007.

[5] S. F. Vatner, M. Park, L. Yan et al., "Adenylyl cyclase type 5 in cardiac disease, metabolism, and aging," The American Journal of Physiology-Heart and Circulatory Physiology, vol. 305, pp. H1-H8, 2013.

[6] L. Yan, J. Y. Park, J.-G. Dillinger et al., "Common mechanisms for calorie restriction and adenylyl cyclase type 5 knockout models of longevity," Aging Cell, vol. 11, no. 6, pp. 1110-1120, 2012.

[7] E. P. Weiss, S. B. Racette, D. T. Villareal et al., "Lower extremity muscle size and strength and aerobic capacity decrease with caloric restriction but not with exercise-induced weight loss," Journal of Applied Physiology, vol. 102, no. 2, pp. 634-640, 2007.

[8] S. C. Faulks, N. Turner, P. L. Else, and A. J. Hulbert, "Calorie restriction in mice: effects on body composition, daily activity, metabolic rate, mitochondrial reactive oxygen species production, and membrane fatty acid composition," The Journals of Gerontology Series A: Biological Sciences and Medical Sciences, vol. 61, no. 8, pp. 781-794, 2006.

[9] K. Flurkey, J. Papaconstantinou, R. A. Miller, and D. E. Harrison, "Lifespan extension and delayed immune and collagen aging in mutant mice with defects in growth hormone production," Proceedings of the National Academy of Sciences of the United States of America, vol. 98, no. 12, pp. 6736-6741, 2001.

[10] M. Holzenberger, J. Dupont, B. Ducos et al., "IGF-1 receptor regulates lifespan and resistance to oxidative stress in mice," Nature, vol. 421, no. 6919, pp. 182-187, 2003.

[11] H. Kurosu, M. Yamamoto, J. D. Clark et al., "Suppression of aging in mice by the hormone Klotho," Science, vol. 309, no. 5742, pp. 1829-1833, 2005.

[12] M. Yamamoto, J. D. Clark, J. V. Pastor et al., "Regulation of oxidative stress by the anti-aging hormone klotho," The Journal of Biological Chemistry, vol. 280, no. 45, pp. 38029-38034, 2005.

[13] E. Migliaccio, M. Giogio, S. Mele et al., "The p66 ${ }^{\text {shc }}$ adaptor protein controls oxidative stress response and life span in mammals," Nature, vol. 402, no. 6759, pp. 309-313, 1999.

[14] A. Mitsui, J. Hamuro, H. Nakamura et al., "Overexpression of human thioredoxin in transgenic mice controls oxidative stress and life span," Antioxidants and Redox Signaling, vol. 4, no. 4, pp. 693-696, 2002.

[15] S. E. Schriner, N. J. Linford, G. M. Martin et al., "Extension of murine life span by overexpression of catalase targeted to mitochondria," Science, vol. 308, no. 5730, pp. 1909-1911, 2005.

[16] X. Yang, T. A. Doser, C. X. Fang et al., "Metallothionein prolongs survival and antagonizes senescence-associated cardiomyocyte diastolic dysfunction: role of oxidative stress," The FASEB Journal, vol. 20, no. 7, pp. 1024-1026, 2006.

[17] A. Benigni, D. Corna, C. Zoja et al., "Disruption of the Ang II type 1 receptor promotes longevity in mice," The Journal of Clinical Investigation, vol. 119, no. 3, pp. 524-530, 2009.

[18] C. Selman, S. Lingard, A. I. Choudhury et al., "Evidence for lifespan extension and delayed age-related biomarkers in insulin receptor substrate 1 null mice," The FASEB Journal, vol. 22, no. 3, pp. 807-818, 2008.

[19] M. Sadagurski, Z. Cheng, A. Rozzo et al., "IRS2 increases mitochondrial dysfunction and oxidative stress in a mouse model of Huntington disease," Journal of Clinical Investigation, vol. 121, no. 10, pp. 4070-4081, 2011.

[20] R. A. Miller, G. Buehner, Y. Chang, J. M. Harper, R. Sigler, and M. Smith-Wheelock, "Methionine-deficient diet extends mouse lifespan, slows immune and lens aging, alters glucose, T4, IGFI and insulin levels, and increases hepatocyte MIF levels and stress resistance," Aging Cell, vol. 4, no. 3, pp. 119-125, 2005.

[21] C. Dell'Agnello, S. Leo, A. Agostino et al., "Increased longevity and refractoriness to $\mathrm{Ca}^{2+}$-dependent neurodegeneration in Surf1 knockout mice," Human Molecular Genetics, vol. 16, no. 4, pp. 431-444, 2007.

[22] A. Bartke, "New findings in gene knockout, mutant and transgenic mice," Experimental Gerontology, vol. 43, no. 1, pp. 11-14, 2008.

[23] Y.-H. Wei and H.-C. Lee, "Oxidative stress, mitochondrial DNA mutation, and impairment of antioxidant enzymes in aging," Experimental Biology and Medicine, vol. 227, no. 9, pp. 671-682, 2002.

[24] V. Gambino, G. de Michele, O. Venezia et al., "Oxidative stress activates a specific p53 transcriptional response that regulates cellular senescence and aging," Aging Cell, vol. 12, no. 3, pp. 435445, 2013.

[25] S. Ikeyama, G. Kokkonen, S. Shack, X.-T. Wang, and N. J. Holbrook, "Loss in oxidative stress tolerance with aging linked to reduced extracellular signal-regulated kinase and Akt kinase activities," The FASEB Journal, vol. 16, no. 1, pp. 114-116, 2002.

[26] J. Sastre, F. V. Pallardó, and J. Viña, “The role of mitochondrial oxidative stress in aging," Free Radical Biology \& Medicine, vol. 35, no. 1, pp. 1-8, 2003.

[27] A. F. G. Slater, C. Stefan, I. Nobel, D. J. Van Den Dobbelsteen, and S. Orrenius, "Signalling mechanisms and oxidative stress in apoptosis," Toxicology Letters, vol. 82-83, pp. 149-153, 1995.

[28] Q. Ran, H. Liang, Y. Ikeno et al., "Reduction in glutathione peroxidase 4 increases life span through increased sensitivity to apoptosis," The Journals of Gerontology, Series A: Biological Sciences and Medical Sciences, vol. 62, no. 9, pp. 932-942, 2007.

[29] A. Csiszar, N. Labinskyy, V. Perez et al., "Endothelial function and vascular oxidative stress in long-lived GH/IGF-deficient Ames dwarf mice," The American Journal of Physiology-Heart and Circulatory Physiology, vol. 295, no. 5, pp. H1882-H1894, 2008.

[30] M. L. Heiman, F. C. Tinsley, J. A. Mattison, S. Hauck, and A. Bartke, "Body composition of prolactin-, growth hormone-, and thyrotropin-deficient Ames dwarf mice," Endocrine, vol. 20, no. 1-2, pp. 149-154, 2003.

[31] A. Sanz, A. Bartke, and G. Barja, "Long-lived ames dwarf mice: oxidative damage to mitochondrial DNA in heart and brain," Journal of the American Aging Association, vol. 25, no. 3, pp. 119$122,2002$. 
[32] X. Qiu, K. Brown, M. D. Hirschey, E. Verdin, and D. Chen, "Calorie restriction reduces oxidative stress by SIRT3-mediated SOD2 activation," Cell Metabolism, vol. 12, no. 6, pp. 662-667, 2010.

[33] D. A. Sinclair, "Toward a unified theory of caloric restriction and longevity regulation," Mechanisms of Ageing and Development, vol. 126, no. 9, pp. 987-1002, 2005.

[34] J. M. Dhahbi, P. L. Mote, J. Wingo et al., "Caloric restriction alters the feeding response of key metabolic enzyme genes," Mechanisms of Ageing and Development, vol. 122, no. 10, pp. 1033-1048, 2001.

[35] R. Weindruch, R. L. Walford, S. Fligiel, and D. Guthrie, "The retardation of aging in mice by dietary restriction: longevity, cancer, immunity and lifetime energy intake," The Journal of Nutrition, vol. 116, no. 4, pp. 641-654, 1986.

[36] K. T. Coschigano, D. Clemmons, L. L. Bellush, and J. J. Kopchick, "Assessment of growth parameters and life span of GHR/BP gene-disrupted mice," Endocrinology, vol. 141, no. 7, pp. 2608-2613, 2000.

[37] S. J. Hauck, J. M. Aaron, C. Wright, J. J. Kopchick, and A. Bartke, "Antioxidant enzymes, free-radical damage, and response to paraquat in liver and kidney of long-living growth hormone receptor/binding protein gene-disrupted mice," Hormone and Metabolic Research, vol. 34, no. 9, pp. 481-486, 2002.

[38] M. Blüher, B. B. Kahn, and C. R. Kahn, "Extended longevity in mice lacking the insulin receptor in adipose tissue," Science, vol. 299, no. 5606, pp. 572-574, 2003.

[39] H. M. Brown-Borg, "Longevity in mice: is stress resistance a common factor?” Age, vol. 28, no. 2, pp. 145-162, 2006.

[40] A. B. Salmon, S. Murakami, A. Bartke, J. Kopchick, K. Yasumura, and R. A. Miller, "Fibroblast cell lines from young adult mice of long-lived mutant strains are resistant to multiple forms of stress," The American Journal of Physiology-Endocrinology and Metabolism, vol. 289, no. 1, pp. E23-E29, 2005.

[41] K. Flurkey, J. Papaconstantinou, and D. E. Harrison, "The Snell dwarf mutation Pit ${ }^{d w}$ can increase life span in mice," Mechanisms of Ageing and Development, vol. 123, no. 2-3, pp. 121-130, 2002.

[42] S. Murakami, A. Salmon, and R. A. Miller, "Multiplex stress resistance in cells from long-lived dwarf mice," The FASEB Journal, vol. 17, no. 11, pp. 1565-1566, 2003.

[43] J. M. Harper, J. E. Wilkinson, and R. A. Miller, "Macrophage migration inhibitory factor-knockout mice are long lived and respond to caloric restriction," The FASEB Journal, vol. 24, no. 7, pp. 2436-2442, 2010.

[44] K. Koga, A. Kenessey, S. R. Powell, C. P. Sison, E. J. Miller, and K. Ojamaa, "Macrophage migration inhibitory factor provides cardioprotection during ischemia/reperfusion by reducing oxidative stress," Antioxidants \& Redox Signaling, vol. 14, no. 7, pp. 1191-1202, 2011.

[45] C. A. Conover and L. K. Bale, "Loss of pregnancy-associated plasma protein A extends lifespan in mice," Aging Cell, vol. 6, no. 5, pp. 727-729, 2007.

[46] C. A. Conover, L. K. Bale, M. T. Overgaard et al., "Metalloproteinase pregnancy-associated plasma protein A is a critical growth regulatory factor during fetal development," Development, vol. 131, no. 5, pp. 1187-1194, 2004.

[47] R. Miskin, O. Tirosh, M. Pardo et al., "AlphaMUPA mice: a transgenic model for longevity induced by caloric restriction," Mechanisms of Ageing and Development, vol. 126, no. 2, pp. 255261, 2005.
[48] O. Tirosh, M. Pardo, B. Schwartz, and R. Miskin, "Longlived $\alpha$ MUPA transgenic mice show reduced SOD2 expression, enhanced apoptosis and reduced susceptibility to the carcinogen dimethylhydrazine," Mechanisms of Ageing and Development, vol. 126, no. 12, pp. 1262-1273, 2005.

[49] L. C. Enns, J. F. Morton, P. R. Treuting et al., "Disruption of protein kinase A in mice enhances healthy aging," PLoS ONE, vol. 4, no. 6, Article ID e5963, 2009.

[50] A. F. Bokov, N. Garg, Y. Ikeno et al., "Does reduced IGF-1R signaling in igflr+/- mice alter aging?" PLOS ONE, vol. 6, no. 11, Article ID e26891, 2011.

[51] H. Liang, E. J. Masoro, J. F. Nelson, R. Strong, C. A. McMahan, and A. Richardson, "Genetic mouse models of extended lifespan," Experimental Gerontology, vol. 38, no. 11-12, pp. 1353-1364, 2003.

[52] C. Selman, J. M. A. Tullet, D. Wieser et al., "Ribosomal protein S6 kinase 1 signaling regulates mammalian life span," Science, vol. 326, no. 5949, pp. 140-144, 2009.

[53] S. H. Um, F. Frigerio, M. Watanabe et al., "Absence of S6K1 protects against age- and diet-induced obesity while enhancing insulin sensitivity," Nature, vol. 431, pp. 200-205, 2004.

[54] A. Bartke, "Long-lived Klotho mice: new insights into the roles of IGF-1 and insulin in aging," Trends in Endocrinology and Metabolism, vol. 17, no. 2, pp. 33-35, 2006.

[55] B. Conti, M. Sanchez-Alavez, R. Winsky-Sommerer et al., "Transgenic mice with a reduced core body temperature have an increased life span," Science, vol. 314, no. 5800, pp. 825-828, 2006.

[56] M. Trinei, M. Giorgio, A. Cicalese et al., "A p53-p66Shc signalling pathway controls intracellular redox status, levels of oxidation-damaged DNA and oxidative stress-induced apoptosis," Oncogene, vol. 21, no. 24, pp. 3872-3878, 2002.

[57] P. Hakimi, J. Yang, G. Casadesus et al., "Overexpression of the cytosolic form of phosphoenolpyruvate carboxykinase (GTP) in skeletal muscle repatterns energy metabolism in the mouse," The Journal of Biological Chemistry, vol. 282, no. 45, pp. 3284432855, 2007.

[58] M. Hotta, F. Tashiro, H. Ikegami et al., "Pancreatic beta cell-specific expression of thioredoxin, an antioxidative and antiapoptotic protein, prevents autoimmune and streptozotocininduced diabetes," The Journal of Experimental Medicine, vol. 188, no. 8, pp. 1445-1451, 1998.

[59] A. Ortega-Molina, A. Efeyan, E. Lopez-Guadamillas et al., "Pten positively regulates brown adipose function, energy expenditure, and longevity," Cell Metabolism, vol. 15, no. 3, pp. 382-394, 2012.

[60] D.-F. Dai, L. F. Santana, M. Vermulst et al., "Overexpression of catalase targeted to mitochondria attenuates murine cardiac aging," Circulation, vol. 119, no. 21, pp. 2789-2797, 2009.

[61] D. L. Johannsen and E. Ravussin, "Can increased muscle ros scavenging keep older animals young and metabolically fit?" Cell Metabolism, vol. 12, no. 6, pp. 557-558, 2010.

[62] P. M. Treuting, N. J. Linford, S. E. Knoblaugh et al., "Reduction of age-associated pathology in old mice by overexpression of catalase in mitochondria," The Journals of Gerontology, Series A, Biological Sciences and Medical Sciences, vol. 63, no. 8, pp. 813824, 2008.

[63] Y. Kanfi, S. Naiman, G. Amir et al., “The sirtuin SIRT6 regulates lifespan in male mice," Nature, vol. 483, no. 7388, pp. 218-221, 2012. 
[64] A. L. Lin, D. A. Pulliam, S. S. Deepa et al., "Decreased in vitro mitochondrial function is associated with enhanced brain metabolism, blood flow, and memory in Surf1-deficient mice," Journal of Cerebral Blood Flow and Metabolism, vol. 33, no. 10, pp. 1605-1611, 2013.

[65] J. Lapointe and S. Hekimi, "Early mitochondrial dysfunction in long-lived Mclk1+/- mice," Journal of Biological Chemistry, vol. 283, no. 38, pp. 26217-26227, 2008.

[66] J. Lapointe, Z. Stepanyan, E. Bigras, and S. Hekimi, "Reversal of the mitochondrial phenotype and slow development of oxidative biomarkers of aging in long-lived Mclk1+/- mice," The Journal of Biological Chemistry, vol. 284, no. 30, pp. 2036420374, 2009.

[67] N. S. Dhalla, R. M. Temsah, and T. Netticadan, "Role of oxidative stress in cardiovascular diseases," Journal of Hypertension, vol. 18, no. 6, pp. 655-673, 2000.

[68] M. Valko, C. J. Rhodes, J. Moncol, M. Izakovic, and M. Mazur, "Free radicals, metals and antioxidants in oxidative stressinduced cancer," Chemico-Biological Interactions, vol. 160, no. 1, pp. 1-40, 2006.

[69] I. Rahman, "The role of oxidative stress in the pathogenesis of COPD: implications for therapy," Treatments in Respiratory Medicine, vol. 4, no. 3, pp. 175-200, 2005.

[70] M. M. H. El Kossi and M. M. Zakhary, "Oxidative stress in the context of acute cerebrovascular stroke," Stroke, vol. 31, no. 8, pp. 1889-1892, 2000.

[71] W. R. Markesbery, "Oxidative stress hypothesis in Alzheimer's disease," Free Radical Biology \& Medicine, vol. 23, no. 1, pp. 134147, 1997.

[72] U. Karunakaran and K.-G. Park, "A systematic review of oxidative stress and safety of antioxidants in diabetes: focus on islets and their defense," Diabetes \& Metabolism Journal, vol. 37, no. 2, pp. 106-112, 2013.

[73] B. P. Oberg, E. McMenamin, F. L. Lucas et al., "Increased prevalence of oxidant stress and inflammation in patients with moderate to severe chronic kidney disease," Kidney International, vol. 65, no. 3, pp. 1009-1016, 2004.

[74] C. F. Brayton, P. M. Treuting, and J. M. Ward, "Pathobiology of aging mice and GEM: background strains and experimental design," Veterinary Pathology, vol. 49, no. 1, pp. 85-105, 2012.

[75] J. K. Sinha, S. Ghosh, and M. Raghunath, "Progeria: a rare genetic premature ageing disorder," The Indian Journal of Medical Research, vol. 139, pp. 667-674, 2014.

[76] B. S. Berlett and E. R. Stadtman, "Protein oxidation in aging, disease, and oxidative stress," The Journal of Biological Chemistry, vol. 272, no. 33, pp. 20313-20316, 1997.

[77] G. Lattanzi, S. Marmiroli, A. Facchini, and N. M. Maraldi, "Nuclear damages and oxidative stress: new perspectives for laminopathies," European Journal of Histochemistry, vol. 56, article e45, 2012.

[78] M. S. Kane, M. E. Lindsay, D. P. Judge et al., "LMNA-associated cardiocutaneous progeria: an inherited autosomal dominant premature aging syndrome with late onset," American Journal of Medical Genetics Part A, vol. 161, no. 7, pp. 1599-1611, 2013.

[79] V. Gremeaux, M. Gayda, R. Lepers, P. Sosner, M. Juneau, and A. Nigam, "Exercise and longevity," Maturitas, vol. 73, no. 4, pp. 312-317, 2012.

[80] C. Goto, Y. Higashi, M. Kimura et al., "Effect of different intensities of exercise on endothelium-dependent vasodilation in humans: role of endothelium-dependent nitric oxide and oxidative stress," Circulation, vol. 108, no. 5, pp. 530-535, 2003.
[81] J. Kruk and E. Duchnik, "Oxidative stress and skin diseases: possible role of physical activity," Asian Pacific Journal of Cancer Prevention, vol. 15, no. 2, pp. 561-568, 2014.

[82] R. C. M. Burneiko, Y. S. Diniz, C. M. Galhardi et al., "Interaction of hypercaloric diet and physical exercise on lipid profile, oxidative stress and antioxidant defenses," Food and Chemical Toxicology, vol. 44, no. 7, pp. 1167-1172, 2006.

[83] U. Laufs, S. Wassmann, T. Czech et al., "Physical inactivity increases oxidative stress, endothelial dysfunction, and atherosclerosis," Arteriosclerosis, Thrombosis, and Vascular Biology, vol. 25, no. 4, pp. 809-814, 2005.

[84] D. Ho, X. Zhao, L. Yan et al., "Adenylyl cyclase type 5 deficiency protects against diet-induced obesity and insulin resistance," Diabetes, 2015.

[85] A. Fernández-Sánchez, E. Madrigal-Santillán, M. Bautista et al., "Inflammation, oxidative stress, and obesity," International Journal of Molecular Sciences, vol. 12, no. 5, pp. 3117-3132, 2011.

[86] M. Ozata, M. Mergen, C. Oktenli et al., "Increased oxidative stress and hypozincemia in male obesity," Clinical Biochemistry, vol. 35, no. 8, pp. 627-631, 2002.

[87] J. F. Keaney Jr., M. G. Larson, R. S. Vasan et al., "Obesity and systemic oxidative stress: clinical correlates of oxidative stress in the Framingham study," Arteriosclerosis, Thrombosis, and Vascular Biology, vol. 23, no. 3, pp. 434-439, 2003.

[88] D. Romero-Alvira, E. Roche, and L. Placer, "Cardiomyopathies and oxidative stress," Medical Hypotheses, vol. 47, no. 2, pp. 137$144,1996$.

[89] D. Cesselli, I. Jakoniuk, L. Barlucchi et al., "Oxidative stressmediated cardiac cell death is a major determinant of ventricular dysfunction and failure in dog dilated cardiomyopathy," Circulation Research, vol. 89, no. 3, pp. 279-286, 2001.

[90] J. Narula, P. Pandey, E. Arbustini et al., "Apoptosis in heart failure: release of cytochrome $\mathrm{c}$ from mitochondria and activation of caspase- 3 in human cardiomyopathy," Proceedings of the National Academy of Sciences of the United States of America, vol. 96, no. 14, pp. 8144-8149, 1999.

[91] P. K. Singal, A. Belló-Klein, F. Farahmand, and V. Sandhawalia, "Oxidative stress and functional deficit in diabetic cardiomyopathy," Advances in Experimental Medicine and Biology, vol. 498, pp. 213-220, 2001.

[92] L. E. Wold, A. F. Ceylan-Isik, and J. Ren, "Oxidative stress and stress signaling: menace of diabetic cardiomyopathy," Acta Pharmacologica Sinica, vol. 26, no. 8, pp. 908-917, 2005.

[93] D. Bandyopadhyay, A. Chattopadhyay, G. Ghosh, and A. G. Datta, "Oxidative stress-induced ischemic heart disease: protection by antioxidants," Current Medicinal Chemistry, vol. 11, no. 3, pp. 369-387, 2004.

[94] N. S. Dhalla, A. B. Elmoselhi, T. Hata, and N. Makino, "Status of myocardial antioxidants in ischemia-reperfusion injury," Cardiovascular Research, vol. 47, no. 3, pp. 446-456, 2000.

[95] A. González, M. A. Fortuño, R. Querejeta et al., "Cardiomyocyte apoptosis in hypertensive cardiomyopathy," Cardiovascular Research, vol. 59, no. 3, pp. 549-562, 2003.

[96] T. Li, I. Danelisen, A. Belló-Klein, and P. K. Singal, "Effects of probucol on changes of antioxidant enzymes in adriamycininduced cardiomyopathy in rats," Cardiovascular Research, vol. 46, no. 3, pp. 523-530, 2000.

[97] G. Condorelli, C. Morisco, G. Stassi et al., "Increased cardiomyocyte apoptosis and changes in proapoptotic and antiapoptotic genes bax and bcl-2 during left ventricular adaptations to chronic pressure overload in the rat," Circulation, vol. 99, no. 23, pp. 3071-3078, 1999. 
[98] M. H. V. M. Jacob, M. R. N. Pontes, A. S. R. Araújo et al., "Aorticbanding induces myocardial oxidative stress and changes in concentration and activity of antioxidants in male Wistar rats," Life Sciences, vol. 79, no. 23, pp. 2187-2193, 2006.

[99] E. Teiger, T.-V. Dam, L. Richard et al., "Apoptosis in pressure overload-induced heart hypertrophy in the rat," The Journal of Clinical Investigation, vol. 97, no. 12, pp. 2891-2897, 1996.

[100] L. Yan, S. F. Vatner, and D. E. Vatner, "Disruption of type 5 adenylyl cyclase prevents $\beta$-adrenergic receptor cardiomyopathy: a novel approach to $\beta$-adrenergic receptor blockade," American Journal of Physiology-Heart and Circulatory Physiology, vol. 307, no. 10, pp. H1521-H1528, 2014.

[101] W. Kolch, "Meaningful relationships: the regulation of the Ras/ Raf/MEK/ERK pathway by protein interactions," Biochemical Journal, vol. 351, no. 2, pp. 289-305, 2000.

[102] T. Finkel and N. J. Holbrook, "Oxidants, oxidative stress and the biology of ageing," Nature, vol. 408, no. 6809, pp. 239-247, 2000.

[103] S.-O. Yoon, C.-H. Yun, and A.-S. Chung, "Dose effect of oxidative stress on signal transduction in aging," Mechanisms of Ageing \& Development, vol. 123, no. 12, pp. 1597-1604, 2002.

[104] A. Lorenzini, M. Tresini, M. Mawal-Dewan et al., "Role of the Raf/MEK/ERK and the PI3K/Akt(PKB) pathways in fibroblast senescence," Experimental Gerontology, vol. 37, no. 10-11, pp. 1149-1156, 2002.

[105] D. Hutter, Y. Yo, W. Chen et al., "Age-related decline in Ras/ ERK mitogen-activated protein kinase cascade is linked to a reduced association between Shc and EGF receptor," Journals of Gerontology-Series A. Biological Sciences and Medical Sciences, vol. 55, no. 3, pp. B125-B134, 2000.

[106] C. Torres, M. K. Francis, A. Lorenzini, M. Tresini, and V. J. Cristofalo, "Metabolic stabilization of MAP kinase phosphatase-2 in senescence of human fibroblasts," Experimental Cell Research, vol. 290, no. 2, pp. 195-206, 2003.

[107] S. Meloche, K. Gopalbhai, B. G. Beatty, S. W. Scherer, and J. Pellerin, "Chromosome mapping of the human genes encoding the MAP kinase kinase MEK1 (MAP2K1) to 15q21 and MEK2 (MAP2K2) to 7q32," Cytogenetics and Cell Genetics, vol. 88, no. 3-4, pp. 249-252, 2000.

[108] X. Zhen, K. Uryu, G. Cai, G. P. Johnson, and E. Friedman, "Ageassociated impairment in brain MAPK signal pathways and the effect of caloric restriction in Fischer 344 rats," Journals of Gerontology, Series A: Biological Sciences and Medical Sciences, vol. 54, no. 12, pp. B539-B548, 1999.

[109] R. A. Miller, G. Garcia, C. J. Kirk, and J. M. Witkowski, "Early activation defects in T lymphocytes from aged mice," Immunological Reviews, vol. 160, pp. 79-90, 1997.

[110] M. Tresini, A. Lorenzini, L. Frisoni, R. G. Allen, and V. J. Cristofalo, "Lack of Elk-1 phosphorylation and dysregulation of the extracellular regulated kinase signaling pathway in senescent human fibroblast," Experimental Cell Research, vol. 269, no. 2, pp. 287-300, 2001.

[111] S. Ikeyama, G. Kokkonen, S. Shack, X.-T. Wang, and N. J. Holbrook, "Loss in oxidative stress tolerance with aging linked to reduced extracellular signal-regulated kinase and Akt kinase activities.," The FASEB journal, vol. 16, no. 1, pp. 114-116, 2002.

[112] M. A. Madsen, C.-C. Hsieh, W. H. Boylston, K. Flurkey, D. Harrison, and J. Papaconstantinou, "Altered oxidative stress response of the long-lived Snell dwarf mouse," Biochemical \& Biophysical Research Communications, vol. 318, no. 4, pp. 998-1005, 2004.

[113] N. Elbourkadi, S. N. Austad, and R. A. Miller, "Fibroblasts from long-lived species of mammals and birds show delayed, but prolonged, phosphorylation of ERK," Aging Cell, vol. 13, no. 2, pp. 283-291, 2014.

[114] P. Fabrizio, L.-L. Liou, V. N. Moy et al., "SOD2 functions downstream of Sch9 to extend longevity in yeast," Genetics, vol. 163, no. 1, pp. 35-46, 2003.

[115] B. S. Mandavilli, J. H. Santos, and B. Van Houten, "Mitochondrial DNA repair and aging," Mutation Research/Fundamental and Molecular Mechanisms of Mutagenesis, vol. 509, no. 1-2, pp. 127-151, 2002.

[116] Y. Zhao, K. K. Kiningham, S.-M. Lin, and D. K. St. Clair, “Overexpression of MnSOD protects murine fibrosarcoma cells (FSaII) from apoptosis and promotes a differentiation program upon treatment with 5-azacytidine: involvement of MAPK and NF $\kappa \mathrm{B}$ pathways," Antioxidants \& Redox Signaling, vol. 3, no. 3, pp. 375386, 2001.

[117] S. R. Plymate, K. H. Haugk, C. C. Sprenger et al., "Increased manganese superoxide dismutase (SOD-2) is part of the mechanism for prostate tumor suppression by Mac25/insulin-like growth factor binding-protein-related protein-1," Oncogene, vol. 22, no. 7, pp. 1024-1034, 2003.

[118] A. Brunet, L. B. Sweeney, J. F. Sturgill et al., "Stress-dependent regulation of FOXO transcription factors by the SIRT1 deacetylase," Science, vol. 303, no. 5666, pp. 2011-2015, 2004.

[119] D. A. Salih and A. Brunet, "FoxO transcription factors in the maintenance of cellular homeostasis during aging," Current Opinion in Cell Biology, vol. 20, no. 2, pp. 126-136, 2008.

[120] A. Sengupta, J. D. Molkentin, and K. E. Yutzey, "FoxO transcription factors promote autophagy in cardiomyocytes," Journal of Biological Chemistry, vol. 284, no. 41, pp. 28319-28331, 2009.

[121] A. Barthel, D. Schmoll, and T. G. Unterman, "FoxO proteins in insulin action and metabolism," Trends in Endocrinology and Metabolism, vol. 16, no. 4, pp. 183-189, 2005.

[122] M. Li, J.-F. Chiu, B. T. Mossman, and N. K. Fukagawa, "Downregulation of manganese-superoxide dismutase through phosphorylation of FOXO3a by Akt in explanted vascular smooth muscle cells from old rats," The Journal of Biological Chemistry, vol. 281, no. 52, pp. 40429-40439, 2006.

[123] G. J. P. L. Kops, T. B. Dansen, P. E. Polderman et al., "Forkhead transcription factor FOXO3a protects quiescent cells from oxidative stress," Nature, vol. 419, no. 6904, pp. 316-321, 2002.

[124] Z. Gerhart-Hines, J. E. Dominy Jr., S. M. Blättler et al., "The cAMP/PKA pathway rapidly activates SIRT1 to promote fatty acid oxidation independently of changes in $\mathrm{NAD}^{+}$, " Molecular Cell, vol. 44, no. 6, pp. 851-863, 2011.

[125] Z. Wang, V. Li, G. C. K. Chan et al., "Adult type 3 adenylyl cyclase-deficient mice are obese," PLoS ONE, vol. 4, no. 9, Article ID e6979, 2009.

[126] T. Onda, Y. Hashimoto, M. Nagai et al., "Type-specific regulation of adenylyl cyclase: selective pharmacological stimulation and inhibition of adenylyl cyclase isoforms," The Journal of Biological Chemistry, vol. 276, no. 51, pp. 47785-47793, 2001.

[127] N. Defer, M. Best-Belpomme, and J. Hanoune, "Tissue specificity and physiological relevance of various isoforms of adenylyl cyclase," The American Journal of Physiology - Renal Physiology, vol. 279, no. 3, pp. F400-F416, 2000.

[128] T. Tang, N. C. Lai, H. K. Hammond et al., "Adenylyl cyclase 6 deletion reduces left ventricular hypertrophy, dilation, dysfunction, and fibrosis in pressure-overloaded female mice," Journal of the American College of Cardiology, vol. 55, no. 14, pp. 14761486, 2010. 
[129] T. Tang, M. H. Gao, N. C. Lai et al., "Adenylyl cyclase type 6 deletion decreases left ventricular function via impaired calcium handling," Circulation, vol. 117, no. 1, pp. 61-69, 2008.

[130] T. Takahashi, T. Tang, N. C. Lai et al., "Increased cardiac adenylyl cyclase expression is associated with increased survival after myocardial infarction," Circulation, vol. 114, no. 5, pp. 388396, 2006.

[131] N. C. Lai, T. Tang, M. H. Gao et al., "Activation of cardiac adenylyl cyclase expression increases function of the failing ischemic heart in mice," Journal of the American College of Cardiology, vol. 51, no. 15, pp. 1490-1497, 2008.

[132] D. M. Roth, H. Bayat, J. D. Drumm et al., "Adenylyl cyclase increases survival in cardiomyopathy," Circulation, vol. 105, no. 16, pp. 1989-1994, 2002.

[133] D. M. Roth, M. H. Gao, N. C. Lai et al., "Cardiac-directed adenylyl cyclase expression improves heart function in murine cardiomyopathy," Circulation, vol. 99, no. 24, pp. 3099-3102, 1999.

[134] A. Guellich, S. Gao, C. Hong et al., "Effects of cardiac overexpression of type 6 adenylyl cyclase affects on the response to chronic pressure overload," The American Journal of Physiology-Heart and Circulatory Physiology, vol. 299, no. 3, pp. H707-H712, 2010.

[135] G. Lappas, G. B. Daou, and M. B. Anand-Srivastava, "Oxidative stress contributes to the enhanced expression of Gi $\alpha$ proteins and adenylyl cyclase signaling in vascular smooth muscle cells from spontaneously hypertensive rats," Journal of Hypertension, vol. 23, no. 12, pp. 2251-2261, 2005.

[136] C. M. Tan, S. Xenoyannis, and R. D. Feldman, "Oxidant stress enhances adenylyl cyclase activation," Circulation Research, vol. 77, no. 4, pp. 710-717, 1995.

[137] S. D. Rees, M. Z. I. Hydrie, J. P. O'Hare et al., "Effects of 16 genetic variants on fasting glucose and type 2 diabetes in South Asians: ADCY5 and GLIS3 variants may predispose to type 2 diabetes," PLoS ONE, vol. 6, no. 9, Article ID e24710, 2011.

[138] K. Iwatsubo, S. Minamisawa, T. Tsunematsu et al., "Direct inhibition of type 5 adenylyl cyclase prevents myocardial apoptosis without functional deterioration," Journal of Biological Chemistry, vol. 279, no. 39, pp. 40938-40945, 2004.

[139] K. Iwatsubo, C. Bravo, M. Uechi et al., "Prevention of heart failure in mice by an antiviral agent that inhibits type 5 cardiac adenylyl cyclase," American Journal of Physiology-Heart and Circulatory Physiology, vol. 302, no. 12, pp. H2622-H2628, 2012. 


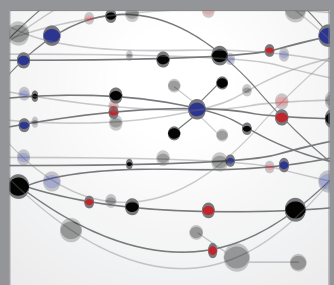

The Scientific World Journal
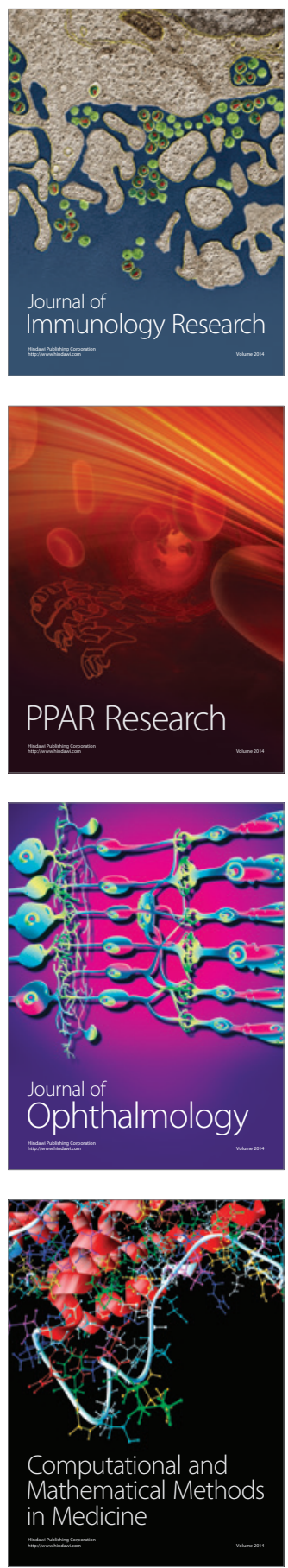

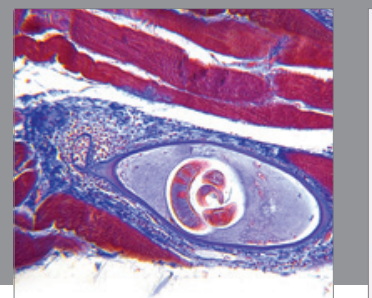

Gastroenterology

Research and Practice
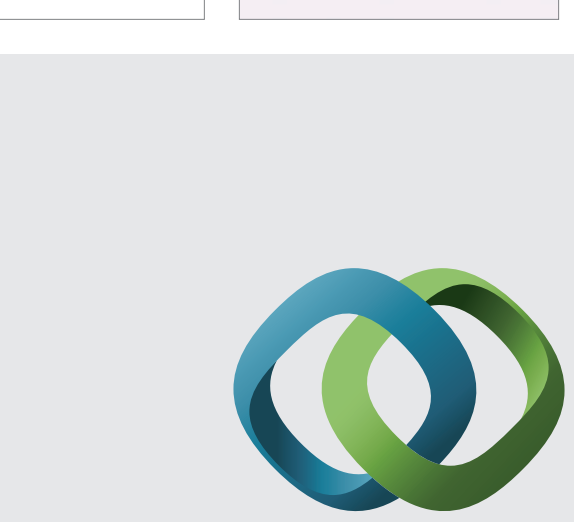

\section{Hindawi}

Submit your manuscripts at

http://www.hindawi.com
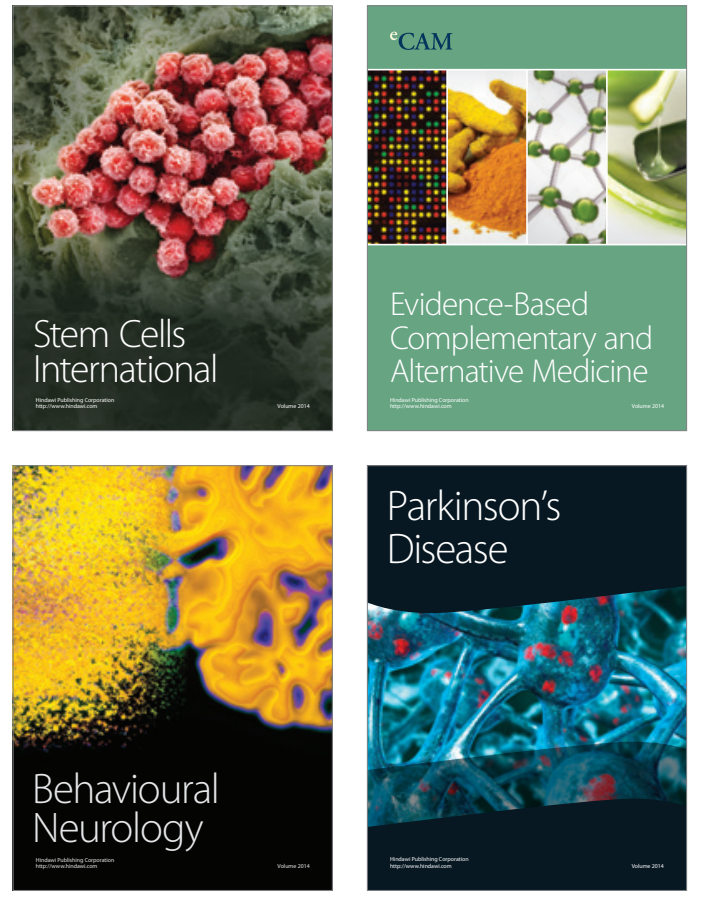
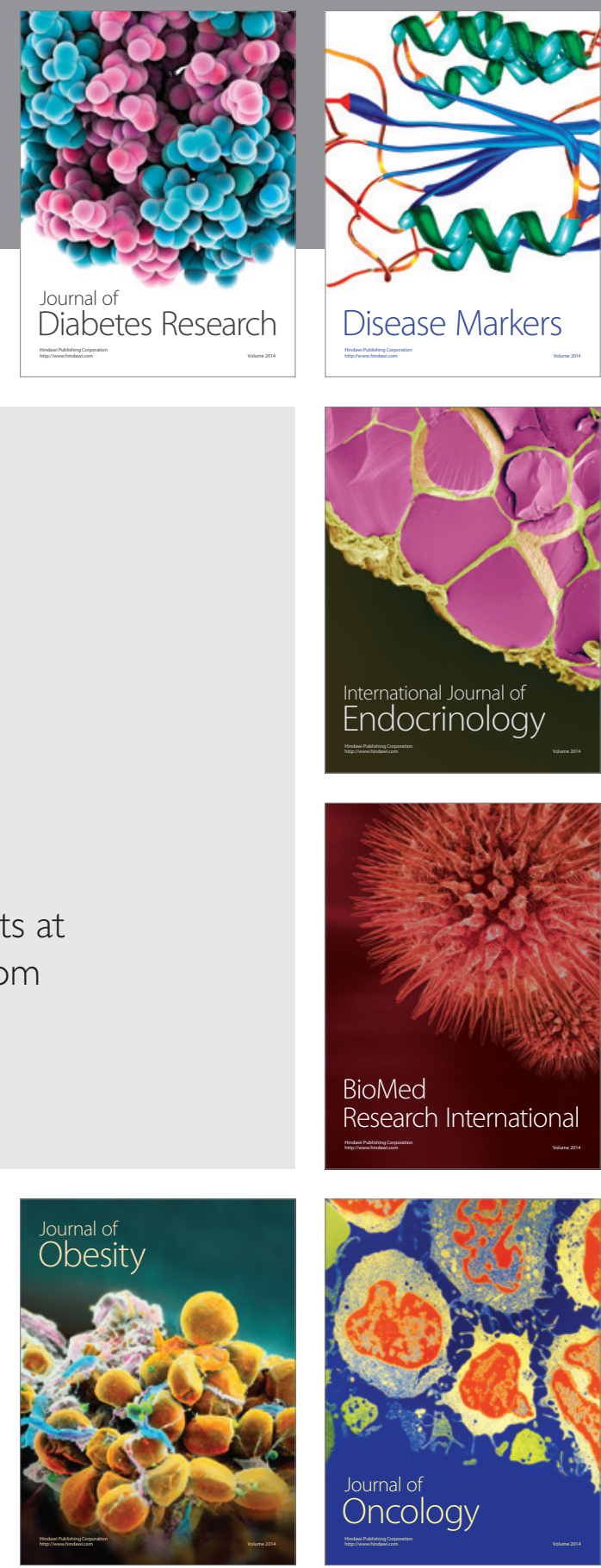

Disease Markers
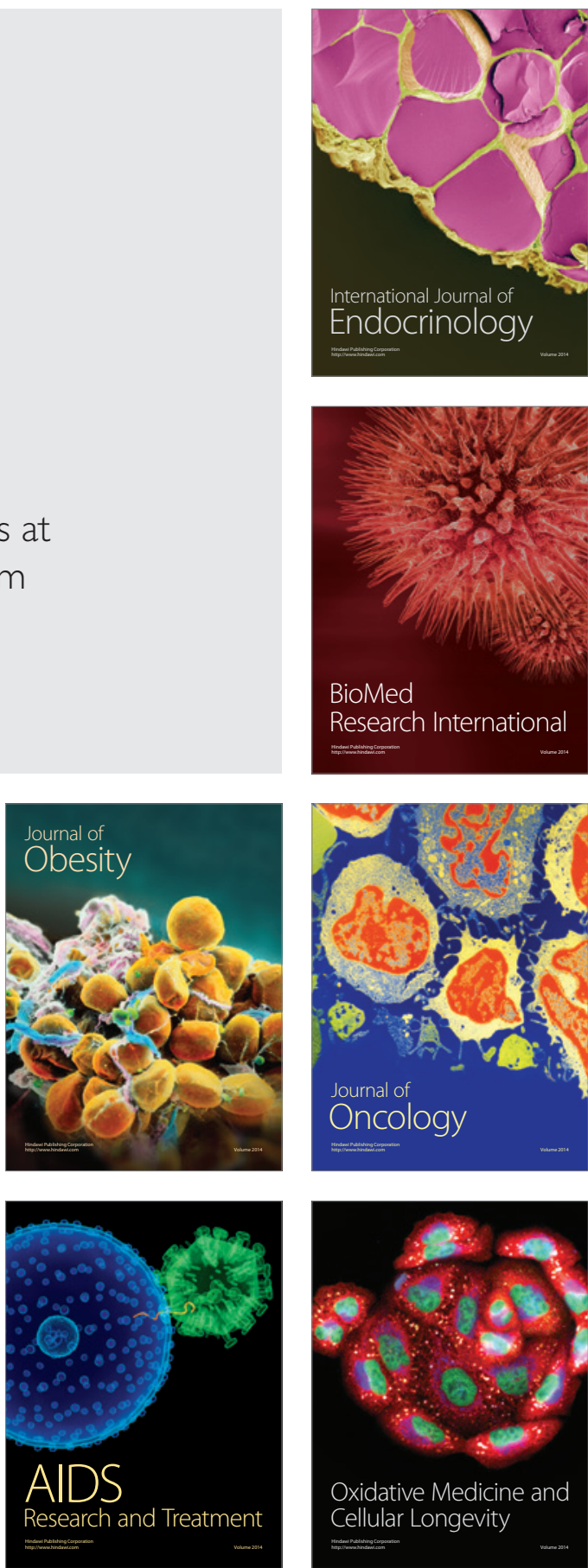